\title{
Uterocervical Angle Measurement Improves Prediction of Preterm Birth in Twin Gestation
}

\author{
Jordan C. Knight, DO ${ }^{1}$ Emily Tenbrink, MD ${ }^{1}$ \\ ${ }^{1}$ Division of Maternal Fetal Medicine, Department of Obstetrics \\ and Gynecology, Indiana University School of Medicine, \\ Indianapolis, Indiana \\ ${ }^{2}$ Division of Clinical Pharmacology, Department of Medicine, \\ Indiana University School of Medicine, Indianapolis, Indiana \\ ${ }^{3}$ Center for Personalized Obstetric Medicine, Valley Perinatal \\ Services, Phoenix, Arizona
}

Am J Perinatol 2018;35:648-654.

\begin{abstract}
Keywords

- cervical length

- multiple gestation

- preterm birth

- ultrasound

- uterocervical angle

Objective Twin pregnancies are associated with an increased risk of spontaneous preterm birth. Our objective was to compare the performance of uterocervical angle to cervical length as predictors of spontaneous preterm birth in this population.

Methods We conducted a retrospective cohort study of twin gestations at a single center from May 2008 to 2016 who received a transvaginal ultrasound for the evaluation of the cervix between $160 / 7$ and $230 / 7$ weeks. The primary outcome was prediction of preterm birth $<28$ and $<32$ weeks by uterocervical angle and cervical length.

Results Among 259 women with twin gestation, the mean gestational age at birth was $34.83 \pm 3.48$ weeks. Receiver operator characteristic curves demonstrated optimal prediction of spontaneous preterm birth prior to 32 weeks at a uterocervical angle $>110^{\circ}$ ( $80 \%$ sensitivity, $82 \%$ specificity) [odds ratio (OR), 15.7 (95\% confidence interval $(\mathrm{Cl}), 7.2-34.4)$ ] versus cervical length $<20 \mathrm{~mm}$ ( $53 \%$ sensitivity, $85 \%$ specificity; $p<0.001, \mathrm{OR}, 6.4[95 \% \mathrm{Cl}, 2.3-17.8])$ and similarly, prior to 28 weeks at a uterocervical angle $>114^{\circ}(\mathrm{OR}, 24.3$ [95\% Cl, 6.7-88.5]) compared with cervical length $<20 \mathrm{~mm}$ (OR, 11.4 [95\% Cl, 3.5-36.7]).

Conclusion Uterocervical angles $>110^{\circ}$ performed better than cervical length for the prediction of spontaneous preterm birth in twin gestations.
\end{abstract}

Approximately 10 to $12 \%$ of pregnancies result in spontaneous preterm birth (sPTB), and it is the leading cause of perinatal morbidity and mortality. ${ }^{1}$ The rate of SPTB has remained relatively constant in recent decades, but the proportion of twin births has increased, a consequence of the increase in both maternal age at conception and access to reproductive technology and treatment. ${ }^{2,3}$ Twin pregnancies are associated with an increased risk of perinatal morbidity and mortality primarily due to spontaneous preterm deliveries. The mean gestational age for delivery is 35.3 weeks'

received

August 6, 2017

accepted after revision

October 12, 2017

published online

November 30, 2017 gestation, and twins account for $23 \%$ of PTBs $<32$ weeks. ${ }^{4,5}$ Having a twin pregnancy alone carries a risk of preterm delivery higher than that of the general population even with a history of a term singleton delivery. ${ }^{6}$

Despite conflicting and limited evidence for successful intervention, different strategies have been proposed for the prediction of SPTB in twin gestations. Short cervix is an etiologic factor that has been correlated with an increased risk of SPTB, and has become standard practice for prediction of SPTB in singleton pregnancies at high risk for $\mathrm{PTB}^{7}{ }^{7}$ A meta-

Copyright @ 2018 by Thieme Medical Publishers, Inc., 333 Seventh Avenue, New York, NY 10001, USA. Tel: +1(212) 584-4662. 
analysis has suggested a cervical length (CL) between 20 and $25 \mathrm{~mm}$ identified prior to 24 weeks' gestation as the cut-off for the prediction of sPTB $<32$ weeks in twin gestations. ${ }^{8,9}$

The anterior uterocervical angle (UCA), defined as the angle between the anterior uterine wall and the cervical canal, was first identified as a marker on magnetic resonance imaging (MRI), and its modification has been associated with effective cervical pessary placement for the prevention of PTB in singleton and twin gestations. ${ }^{10-13}$ An obtuse UCA has been associated with gestational age at delivery in singleton gestations, and investigations of UCA suggest that it may be a useful parameter to identify patients at risk for preterm delivery in that population..$^{14,15}$ The aim of our study was to compare the performance of UCA to $\mathrm{CL}$ as sonographic predictors of SPTB in patients with twin gestation.

\section{Methods}

We conducted a retrospective cohort study of twin gestations at a single academic center from May 2008 to 2016 who received a transvaginal ultrasound for the evaluation of the cervix between $160 / 7$ and 22 6/7 weeks. The study was approved by the institutional review board (IRB) at our institution as a retrospective protocol. Subjects anticipated to deliver within our health system were identified by a key word search "transvaginal" and "fetal number: 2" in our ultrasound imaging system (ViewPoint 5, GE Healthcare, Chicago, IL). During the study period, it was standard protocol at our institution to routinely evaluate the cervix with transvaginal ultrasound in the second trimester (1623 weeks) in all patients with multiple gestation to determine a baseline CL. This screen was independent of obstetric history or current pregnancy symptomatology. Transvaginal ultrasound images of the cervix were obtained by CL education and review (CLEAR)-certified ultrasonographers monitored by maternal fetal medicine staff. ${ }^{12}$ Transvaginal images at the time of anatomical survey studies were accessed and measured for UCA. Additionally, the CLs were remeasured on corresponding images. CL was defined as a linear measurement from the internal os to the external os of the cervix. UCA was defined as the angle at the internal os created by the intersecting lines drawn from the internal to external os and a second line parallel to the lower aspect of the anterior uterine wall, passing through the internal cervical os. The first line was formed by a straight, uninterrupted line connecting the internal os to the external os. To create the angle, a second caliper was placed from the innermost portion of intact measurable cervix and extended to the lower uterine segment (- Fig. 1). The UCA was measured from three adequate transvaginal images at the same gestational age, and the mean measurement was calculated. All UCA and CL measurements were obtained by a single maternal fetal medicine physician masked to pregnancy outcome. Medical records were reviewed to obtain maternal demographic data, medical comorbidities, obstetric history, and delivery data. Gestational age and chorionicity were determined by a first trimester ultrasound.

Women were included in the analysis if they were between the ages of 16 and 50 years, carrying either dichorionicdiamniotic or monochorionic-diamniotic twin gestations with resultant birth of two living neonates, delivered in our institutional system between May 1, 2008 and May 31, 2016, and had transvaginal ultrasound CL screening at our prenatal diagnosis center between 16 0/7 and 23 0/7 weeks' gestation. Candidates were excluded if there were absent or suboptimal transvaginal CL images available for review, incomplete obstetric, medical, or delivery records, monochorionic-monoamniotic twin gestations, and medically indicated preterm delivery. These indications included preeclampsia with severe features, morbidly adherent placenta, intrauterine growth restriction with absent end-diastolic or reverse end-diastolic umbilical artery Doppler studies, or nonreassuring antepartum fetal heart monitoring. Women were also excluded if the pregnancy was complicated by an intrauterine fetal demise (IUFD) of one or both twins, had selective reduction of one twin, if a "vanishing twin" was diagnosed after the first
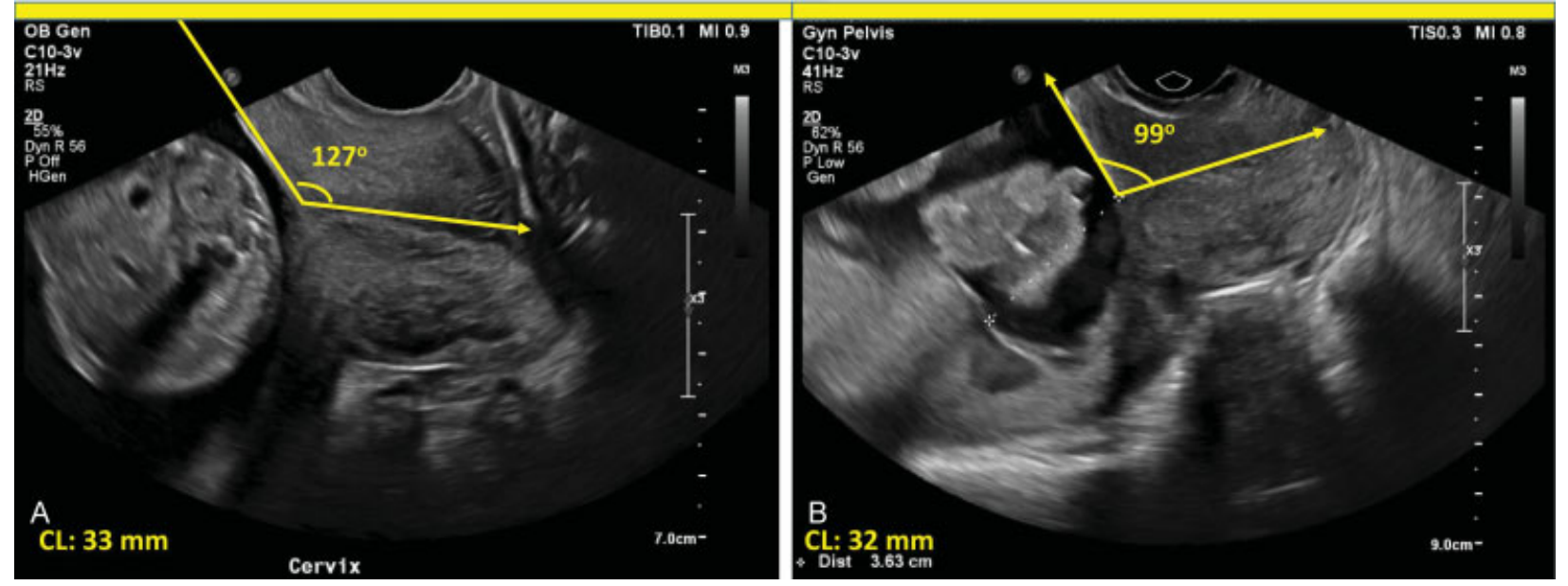

Fig. 1 Transvaginal ultrasound measurement of anterior uterocervical angle (UCA). The UCA is formed by the intersecting lines drawn from the internal to external os and a second line parallel to the lower aspect of the anterior uterine wall, passing through the internal cervical os. (A) UCA $>110$ degrees, CL 33 mm; (B) UCA <110 degrees, CL 32 mm. 
trimester, or if there were complications of monochorionicity including twin-to-twin transfusion syndrome.

PTB was defined as gestational age at birth less than 36 weeks' gestation. The primary outcome was prediction of PTB $<28$ and $<32$ weeks by UCA and CL. Statistical analysis of baseline demographic and medical characteristics of women with delivery prior to 36 weeks were compared with women with term delivery using chi-square tests and Student's $t$-tests. Hierarchical multiple regression analysis was performed to control for the effect of $\mathrm{CL}$ on gestational age of delivery to determine the effect UCA had on gestational age at delivery. Receiver operator characteristic (ROC) curves were developed to determine an optimal UCA for the prediction of SPTB at $<28$ and $<32$ weeks' gestation. Binary logistic regression was then used to determine the risk of preterm delivery based on the thresholds for optimal sensitivity/specificity in the ROC curves. Statistical significance was defined as $p<0.05$. Statistical analyses were conducted using IBM SPSS Statistics version 23.0 (Armonk, NY).

\section{Results}

A total of 391 women anticipated to delivery within our health system were identified as having a twin gestation with a second trimester transvaginal ultrasound during the study period. After 132 women were excluded, 259 (66\%) women remained (-Fig. 2). Among the 259 women, the mean gestational age at birth was $34.8 \pm 3.48$, and the median gestational age at birth was 36.1 weeks. In patients with sPTB $<36$ weeks, the mean gestational age at birth was $31.9 \pm 3.4$ weeks compared with $37.1 \pm 0.8$ weeks in those that delivered at term $(p<0.001)$. The kappa coefficient was 0.87 for intraobserver variability, evident of strong agreement between the three separately measured UCAs.

The rate of sPTB was $44.8 \%(n=116)$ at $<36$ weeks, $16.9 \%$ $(n=44)$ at $<32$ weeks, and $6.9 \%(n=18)$ at $<28$ weeks of gestation. Women who delivered preterm were similar to those who delivered $>36$ weeks with respect to race, parity, chorionicity, history of preterm delivery, use of progesterone supplementation, use of assisted reproductive technology, body mass index (BMI), maternal diabetes, mode of delivery, and gestational age at the screening ultrasound. However, compared with women who delivered $>36$ weeks, women who delivered preterm were more likely to be smokers $(p<0.03)$. In this cohort, women who delivered $>36$ weeks' gestation were older $(p<0.01)$ and exhibited maternal hypertensive disease $(p<0.05)$ compared with those delivering prior to 36 weeks (-Table 1). Univariate analysis was performed of the cervical parameters, smoking, and hypertensive history to gestational age at delivery. Of these variables, only UCA $(R=0.684, p<0.001)$ and CL $(R=0.396, p<0.001)$ were strongly predictive of gestational age at birth. Hierarchical regression analysis showed that when controlled for $\mathrm{CL}$, the addition of the UCA improved prediction of gestational age at birth $\left(R^{2}\right.$ change $\left.=0.339\right)$. When controlled for UCA, regression analysis showed that CL only modestly improved prediction of gestational age at birth $\left(R^{2}\right.$ change $\left.=0.027\right)$.

ROC curves were generated to evaluate UCA and CL for prediction of delivery prior to 32 and 28 weeks' gestation (-Fig.3). UCA demonstrated improved prediction of delivery prior to 32 weeks with an area under the curve of 0.887 $[p<0.001$; standard error (SE), $\pm 0.02 ; 95 \%$ confidence interval (CI), 0.84-0.93] compared with $0.709(p<0.001$; $\mathrm{SE}, \pm 0.04 ; 95 \% \mathrm{CI}, 0.62-0.79$ ) for CL. A point on the ROC curve which revealed optimal performance of UCA was found at $110^{\circ}$ with a sensitivity of $80 \%$ and specificity of $82 \%$. The negative predictive value was $97.1 \%$. The threshold of $20 \mathrm{~mm}$ demonstrated 53\% sensitivity, $85 \%$ specificity, and $96 \%$ negative predictive value for spontaneous delivery prior to 32 weeks in our cohort.

ROC curves were also performed to evaluate prediction of delivery prior to 28 weeks. In women with twin gestation and delivery $<28$ weeks, the area under the curve for UCA was 0.882 ( $p<0.001$; SE, \pm 0.03 ; 95\% CI, 0.83-0.94) compared with an area under the curve of $0.736(p=0.001$; $\mathrm{SE}, \pm 0.06 ; 95 \% \mathrm{CI}, 0.61-0.86$ ) for CL. Optimal performance of UCA was found at $114^{\circ}$ with a sensitivity of $80 \%$ and specificity of $84 \%$. The negative predictive value was $99 \%$.

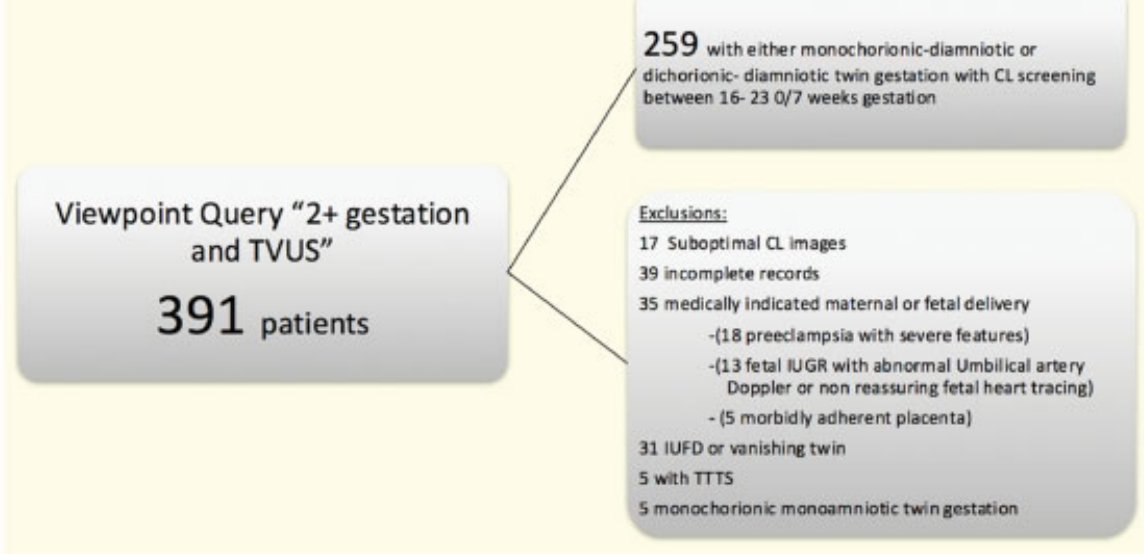

Fig. 2 Flow chart of patients who met inclusion/exclusion criteria for the study population. 
Table 1 Demographic characteristics of cohort

\begin{tabular}{|c|c|c|c|c|}
\hline & $\begin{array}{l}\text { Total } \\
n=259\end{array}$ & $\begin{array}{l}\text { Delivery }<36 \text { weeks } \\
n=116(44.8 \%)\end{array}$ & $\begin{array}{l}\text { Delivery }>36 \text { weeks } \\
n=143(55.2 \%)\end{array}$ & p-Value \\
\hline Age (SD) & $\begin{array}{l}30.46 \\
(5.87)\end{array}$ & $\begin{array}{l}29.42 \\
(5.83)\end{array}$ & $\begin{array}{l}31.31 \\
(5.76)\end{array}$ & 0.01 \\
\hline Gravidity & $\begin{array}{l}2.57 \\
(1.94)\end{array}$ & $\begin{array}{l}2.67 \\
(1.99)\end{array}$ & $\begin{array}{l}2.48 \\
(1.90)\end{array}$ & 0.43 \\
\hline Parity & $\begin{array}{l}0.90 \\
(1.19)\end{array}$ & $\begin{array}{l}0.99 \\
(1.37)\end{array}$ & $\begin{array}{l}0.83 \\
(1.01)\end{array}$ & 0.28 \\
\hline $\begin{array}{l}\text { Dichorionic-diamniotic } \\
\text { Monochorionic-diamniotic }\end{array}$ & $\begin{array}{l}209 \\
50\end{array}$ & $\begin{array}{l}91 \\
25\end{array}$ & $\begin{array}{l}118 \\
25\end{array}$ & $\begin{array}{l}0.41 \\
0.41\end{array}$ \\
\hline \multicolumn{5}{|l|}{ Race } \\
\hline Caucasian & 187 & 82 & 105 & 0.62 \\
\hline African American & 46 & 24 & 22 & 0.27 \\
\hline Asian & 11 & 4 & 7 & 0.57 \\
\hline Hispanic & 11 & 5 & 6 & 0.96 \\
\hline Other & 4 & 1 & 3 & 0.42 \\
\hline BMI (SD) & $\begin{array}{l}30.89 \\
(7.32)\end{array}$ & $\begin{array}{l}30.62 \\
(7.54)\end{array}$ & $\begin{array}{l}31.10 \\
(7.13)\end{array}$ & 0.60 \\
\hline ART & 67 & 29 & 38 & 0.77 \\
\hline Smoker & 34 & 21 & 13 & 0.03 \\
\hline Hypertensive disease & 47 & 15 & 32 & 0.05 \\
\hline gDM/DM & 28 & 13 & 15 & 0.85 \\
\hline History of PTD & 22 & 11 & 11 & 0.61 \\
\hline Progesterone use & 10 & 4 & 6 & 0.76 \\
\hline Cerclage & 10 & 7 & 3 & 0.10 \\
\hline PPROM & 46 & 42 & 4 & $<0.001$ \\
\hline \multicolumn{5}{|l|}{ Mode of delivery } \\
\hline Cesarean & 187 & 81 & 106 & 0.44 \\
\hline Vaginal & 65 & 28 & 37 & 0.74 \\
\hline Vaginal/cesarean & 7 & 7 & 0 & 0.01 \\
\hline UCA, degrees (SD) & $\begin{array}{l}104.55 \\
(13.45)\end{array}$ & $\begin{array}{l}113.49 \\
(8.66)\end{array}$ & $\begin{array}{l}98.69 \\
(5.75)\end{array}$ & $<0.001$ \\
\hline $\mathrm{CL}, \mathrm{mm}(\mathrm{SD})$ & $\begin{array}{l}38.21 \\
(9.76)\end{array}$ & $\begin{array}{l}34.64 \\
(11.20)\end{array}$ & $\begin{array}{l}41.11 \\
(7.21)\end{array}$ & $<0.001$ \\
\hline $\begin{array}{l}\text { Gestational age at ultrasound } \\
\text { screen in weeks (SD) }\end{array}$ & $\begin{array}{l}19.84 \\
(1.77)\end{array}$ & $\begin{array}{l}19.99 \\
(1.78)\end{array}$ & $\begin{array}{l}19.73 \\
(1.76)\end{array}$ & 0.24 \\
\hline Mean gestational age at birth in wk (SD) & $\begin{array}{l}34.83 \\
(3.48)\end{array}$ & $\begin{array}{l}31.98 \\
(3.43)\end{array}$ & $\begin{array}{l}37.13 \\
(0.78)\end{array}$ & \multirow[t]{2}{*}{$<0.001$} \\
\hline Median gestational age at birth in wk & 36.14 & 32.86 & 37.00 & \\
\hline
\end{tabular}

Abbreviations: ART, assisted reproductive technology; BMI, body mass index; $\mathrm{CL}$, cervical length; gDM/DM, gestational diabetes mellitus/diabetes mellitus; PPROM, preterm premature rupture of membranes; PTD, preterm delivery; SD, standard deviation; UCA, uterocervical angle.

The threshold of $20 \mathrm{~mm}$ demonstrated 35\% sensitivity, 95\% specificity, and $94 \%$ negative predictive value for spontaneous delivery prior to 28 weeks' gestation.

Binary logistic regression was later performed to estimate the risk of delivery prior to 32 and 28 weeks using the UCA thresholds from the ROC analysis. UCA $>110^{\circ}$ conferred an odds ratio (OR) of 15.7 ( $p<0.001 ; 95 \% \mathrm{CI}, 7.2-34.4$ ) for delivery prior to 32 weeks, and UCA $>114^{\circ}$ an OR of 24.3 $(p<0.001 ; 95 \% \mathrm{CI}, 6.7-88.5)$ for delivery prior to 28 weeks. In comparison, $\mathrm{CL}<20 \mathrm{~mm}$ had an OR of 6.4 ( $p<0.001 ; 95 \%$ $\mathrm{CI}, 2.3-17.8)$ and OR of $11.4(p=0.001 ; 95 \% \mathrm{CI}, 3.5-36.7)$ prior to 32 and 28 weeks, respectively. 

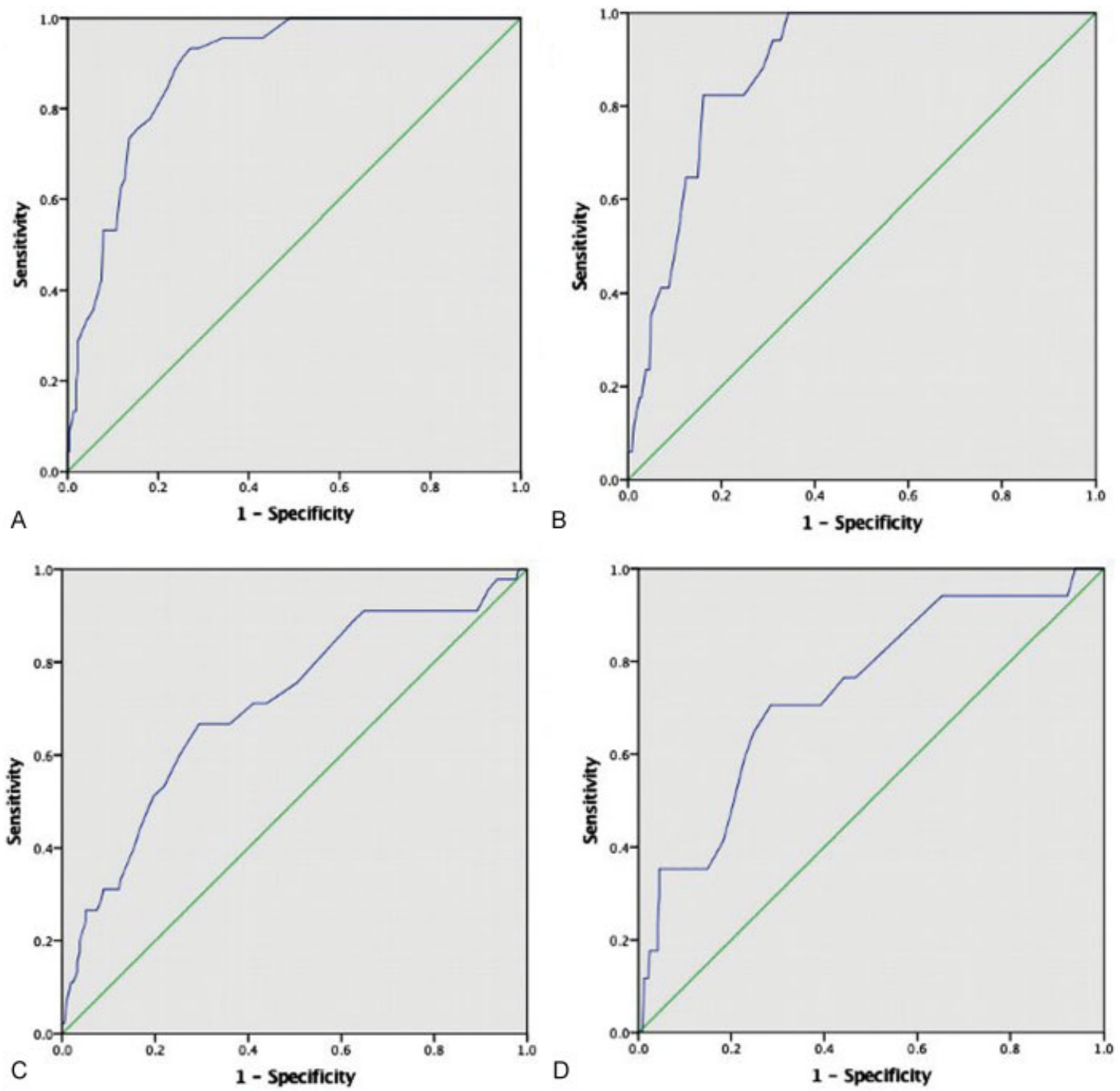

Fig. 3 Comparison of receiver operator characteristic (ROC) curves for uterocervical angle (UCA) and cervical length (CL) for prediction of spontaneous preterm birth in twin gestations. (A) UCA <32 weeks [area under the curve (AUC), 0.887]; (B) UCA <28 weeks (AUC, 0.882 ); (C) CL $<32$ weeks (AUC, 0.709); (D) $\mathrm{CL}<28$ weeks (AUC, 0.736).

\section{Discussion}

We performed a retrospective cohort study to independently compare the performance of the anterior UCA measurement to $\mathrm{CL}$ during the midtrimester for prediction of spontaneous preterm delivery in twin gestations. In our study, UCA performed well compared with CL as a screening tool. Our results indicate that the UCA demonstrated a higher sensitivity for SPTB at less than 28 and 32 weeks' gestation compared with CL of $20 \mathrm{~mm}$. An obtuse UCA angle of $>110^{\circ}$ performed superiorly to conventional CL measurement thresholds during the second trimester when determining the likelihood of SPTB in twins. These data imply that when a patient does not screen positive with an obtuse UCA measurement $>110^{\circ}$, it is unlikely that she will go on to deliver preterm and would not require additional cervical monitoring.

A common question regarding use of ultrasound screening and/or surveillance in twin gestations has been how to prevent preterm delivery in patients identified at risk. Compared with singleton gestations, conflicting data have been published regarding the success of cerclage, progesterone, or pessary placement in the twin population. Cerclage has been associated with an increased risk of preterm delivery in one study, ${ }^{16}$ but other data suggest that it can be beneficial in twin pregnancies with either a cervix less than $15 \mathrm{~mm},{ }^{17}$ a dilated cervix, ${ }^{18,19}$ or dichorionic-diamniotic twin gestations with short cervix. ${ }^{20}$ With regards to progesterone use, a metaanalysis in 2015 suggests that vaginal progesterone (not 17-hydroxyprogesterone) supplementation is associated with improved outcomes in twins with a short cervix. ${ }^{21}$

However, recent studies evaluating cervical pessary use in twins has shown benefit in patients with short cervix, ${ }^{12,22}$ and modification of the anterior UCA has been associated with effective cervical pessary placement. ${ }^{10,13}$ In a normal advancing gestation, the force of the gravid uterus is directed down toward the cervix, and this is accentuated further and earlier in multiple gestations. Depending upon the angle of inclination of the cervix, the cervical canal may be considered either "closed" 
in cases of an acute UCA or "open" in cases of an obtuse UCA. Until recently, the anterior UCA has only been used to evaluate a small cohort of patients with singleton gestations being treated with a cervical pessary. ${ }^{13}$ Dziadosz et $\mathrm{al}^{15}$ showed that a UCA $>105^{\circ}$ during the second trimester has been associated with an increased risk for SPTB less than 34-week gestation in singleton gestations, and in this study, the UCA performed better than CL for the assessment of preterm delivery.

Based on the theories proposed in the cervical pessary studies, we presumed that the positioning and shape of the gravid uterus affects the mechanical function of the cervix as pregnancy advances, and this may manifest sooner in pregnancies with twin gestations. Physiologic weight distribution can put pressure on the internal os, which can directly affect the anterior UCA. ${ }^{23}$ A wider UCA presumably provides an increased loading force which may lead to increased effacement. ${ }^{23,24}$

The use of CL as a screening tool to estimate risk of PTB has been extensively studied, and has remained the most consistent tool applied. The American College of Obstetricians and Gynecologists (ACOG) guidelines recommend that a patient with a history of PTB have $\mathrm{CL}$ screening in the midtrimester. ${ }^{25}$ However, there has been no consensus for routine screening of $\mathrm{CL}$ in patients with twin gestation that do not have a history of preterm delivery. A recent retrospective cohort published in 2016 looked to determine whether the rate of change in CL was associated with SPTB in twins, and they found that a decrease in $>2 \mathrm{~mm} /$ week of $\mathrm{CL}$ identified patients at increased risk of SPTB less than 35 weeks' gestation. ${ }^{26}$ To date, there have only been retrospective studies supporting the utility of a single UCA measurement in the midtrimester as an additional screening tool to assess preterm delivery risk. Although limited, it has proven a useful ultrasound marker to identify patients at high risk in the singleton population.

Our study has several limitations. The retrospective nature of the study increases the risk for bias. However, to limit measurement bias, all sonographers used the standardized protocol to measure $\mathrm{CL}$, and all of the UCA measurements were performed by a single provider blinded to patient outcome. Second, our study was from a single academic center and may be subject to selection bias from the practice patterns of the faculty physicians. Nonetheless, in our study population, the two groups of women were similar and allowed for the evaluation of a considerable sample of transvaginal images from twin gestations. Finally, since we only evaluated UCA at one point during the second trimester, it is unknown whether serial evaluation of the UCA would correlate more strongly with risk of sPTB in twins. Future multicentered, prospective trials to increase sample size are needed to define the role of UCA as a useful screening tool in this population.

In conclusion, UCA measurement is a simple technique that can be completed on a standard mid-sagittal transvaginal cervical image. It has recently been shown to aid in the prediction of PTB risk in singleton gestations. Our study suggests that a screening measurement of the UCA during the midtrimester may have improved utility as a predictor of risk of SPTB in patients with a twin gestation. Although there is mixed data regarding preventative intervention, improved identification of patients at increased risk could improve patient counseling and may allow time for other interventions to optimize the event of a preterm delivery. This study showed that UCA can be used independently or as an adjunct measurement tool with CL for a stronger prediction of preterm delivery. Future prospective studies will be needed to confirm our findings and better define the role of UCA as a tool for the prediction of SPTB in patients with twin gestation.

Note

This paper was presented as a poster at the 37th Annual Pregnancy Meeting of the Society of Maternal-Fetal-Medicine, Las Vegas, NV, January 24-29, 2017; and as an oral presentation at the American Institute of Ultrasound in Medicine Convention, Orlando, FL, March 25-29, 2017.

\section{Conflict of Interest}

None.

\section{References}

1 Martin JA. Births: Final Data for 2014. Natl Vital Stat Rep 2015; 64:1-65

2 McClamrock HD, Jones HW Jr, Adashi EY. Ovarian stimulation and intrauterine insemination at the quarter centennial: implications for the multiple births epidemic. Fertil Steril 2012;97(04): 802-809

3 Ananth CV, Chauhan SP. Epidemiology of twinning in developed countries. Semin Perinatol 2012;36(03):156-161

4 American College of Obstetricians and Gynecologists Committee on Practice Bulletins-Obstetrics; Society for Maternal-Fetal Medicine; ACOG Joint Editorial Committee. ACOG Practice Bulletin \#56: multiple gestation: complicated twin, triplet, and high-order multifetal pregnancy. Obstet Gynecol 2004;104(04):869-883

5 Goldenberg RL, Iams JD, Das A, et al; National Institute of Child Health and Human Development Maternal-Fetal Medicine Units Network. The Preterm Prediction Study: sequential cervical length and fetal fibronectin testing for the prediction of spontaneous preterm birth. Am J Obstet Gynecol 2000;182(03):636-643

6 Kazemier BM, Buijs PE, Mignini L, Limpens J, de Groot CJM, Mol BWJ; EBM CONNECT. Impact of obstetric history on the risk of spontaneous preterm birth in singleton and multiple pregnancies: a systematic review. BJOG 2014;121(10):1197-1208

7 Iams JD, Goldenberg RL, Meis PJ, et al; National Institute of Child Health and Human Development Maternal Fetal Medicine Unit Network. The length of the cervix and the risk of spontaneous premature delivery. N Engl J Med 1996;334(09):567-572

8 Conde-Agudelo A, Romero R, Hassan SS, Yeo L. Transvaginal sonographic cervical length for the prediction of spontaneous preterm birth in twin pregnancies: a systematic review and metaanalysis. Am J Obstet Gynecol 2010;203(02):128.e1-128.e12

9 Goldenberg RL, Iams JD, Miodovnik M, et al; National Institute of Child Health and Human Development Maternal-Fetal Medicine Units Network. The preterm prediction study: risk factors in twin gestations. Am J Obstet Gynecol 1996;175(4 Pt 1):1047-1053

10 Arabin B, Alfirevic Z. Cervical pessaries for prevention of spontaneous preterm birth: past, present and future. Ultrasound Obstet Gynecol 2013;42(04):390-399

11 Goya M, Pratcorona L, Merced C, et al; Pesario Cervical para Evitar Prematuridad (PECEP) Trial Group. Cervical pessary in pregnant women with a short cervix (PECEP): an open-label randomised controlled trial. Lancet 2012;379(9828):1800-1806 
12 Goya M, de la Calle M, Pratcorona L, et al; PECEP-Twins Trial Group. Cervical pessary to prevent preterm birth in women with twin gestation and sonographic short cervix: a multicenter randomized controlled trial (PECEP-Twins). Am J Obstet Gynecol 2016;214(02):145-152

13 Cannie MM, Dobrescu O, Gucciardo L, et al. Arabin cervical pessary in women at high risk of preterm birth: a magnetic resonance imaging observational follow-up study. Ultrasound Obstet Gynecol 2013;42(04):426-433

14 Sochacki-Wójcicka N, Wojcicki J, Bomba-Opon D, Wielgos M. Anterior cervical angle as a new biophysical ultrasound marker for prediction of spontaneous preterm birth. Ultrasound Obstet Gynecol 2015;46(03):377-378

15 Dziadosz M, Bennett TA, Dolin C, et al. Uterocervical angle: a novel ultrasound screening tool to predict spontaneous preterm birth. Am J Obstet Gynecol 2016;215(03):376.e1-376.e7

16 Berghella V, Odibo AO, To MS, Rust OA, Althuisius SM. Cerclage for short cervix on ultrasonography: meta-analysis of trials using individual patient-level data. Obstet Gynecol 2005;106 (01):181-189

17 Roman A, Rochelson B, Fox NS, et al. Efficacy of ultrasoundindicated cerclage in twin pregnancies. Am J Obstet Gynecol 2015;212(06):788.e1-788.e6

18 Rebarber A, Bender S, Silverstein M, Saltzman DH, Klauser CK, Fox NS. Outcomes of emergency or physical examination-indicated cerclage in twin pregnancies compared to singleton pregnancies. Eur J Obstet Gynecol Reprod Biol 2014;173:43-47
19 Miller ES, Rajan PV, Grobman WA. Outcomes after physical examination-indicated cerclage in twin gestations. Am J Obstet Gynecol 2014;211(01):46.e1-46.e5

20 Houlihan C, Poon LCY, Ciarlo M, Kim E, Guzman ER, Nicolaides KH. Cervical cerclage for preterm birth prevention in twin gestation with short cervix: a retrospective cohort study. Ultrasound Obstet Gynecol 2016;48(06):752-756

21 Schuit E, Stock S, Rode L, et al; Global Obstetrics Network (GONet) collaboration. Effectiveness of progestogens to improve perinatal outcome in twin pregnancies: an individual participant data meta-analysis. BJOG 2015;122(01):27-37

22 Fox NS, Gupta S, Lam-Rachlin J, Rebarber A, Klauser CK, Saltzman DH. Cervical pessary and vaginal progesterone in twin pregnancies with a short cervix. Obstet Gynecol 2016;127(04):625-630

23 Myers KM, Feltovich H, Mazza E, et al. The mechanical role of the cervix in pregnancy. J Biomech 2015;48(09):1511-1523

24 Fernandez M, House M, Jambawalikar S, et al. Investigating the mechanical function of the cervix during pregnancy using finite element models derived from high-resolution 3D MRI. Comput Methods Biomech Biomed Engin 2016;19(04):404-417

25 American College of Obstetrics and Gynecology. ACOG Practice Bulletin Number 130, October, 2012 (reaffirmed 2016). Prediction and prevention of preterm birth. Obstet Gynecol 2012;120(04):964-973

26 Moroz LA, Brock CO, Govindappagari S, Johnson DL, Leopold BH, Gyamfi-Bannerman C. Association between change in cervical length and spontaneous preterm birth in twin pregnancies. Am J Obstet Gynecol 2017;216(02):159.e1-159.e7 